\title{
2019-nCoV/COVID-19 - Approaches to Viral Vaccine Development and Preventive Measures
}

\author{
Muhammad Bilal $^{1}$ (D), Muhammad Shahzad Nazir ${ }^{2}$ (D), Roberto Parra-Saldivar ${ }^{3}$ (D) \\ and Hafiz M.N. Iqbal ${ }^{3 *}$
}

${ }^{1}$ School of Life Science and Food Engineering, Huaiyin Institute of Technology, Huaian 223003, China.

${ }^{2}$ Faculty of Automation, Huaiyin Institute of Technology, Huaian 223003, China. ${ }^{3}$ Tecnologico de Monterrey, School of Engineering and Sciences, Campus Monterrey, Ave. Eugenio Garza Sada 2501, Monterrey, N.L., CP 64849, Mexico.

\begin{abstract}
The severity assessment of COVID-19 and transmissibility of newly emerged novel-Coronavirus (2019-nCoV) can effectively help and support to quantify the ongoing pandemic risks. Among several epidemiological measures against COVID-19 severity, the case fatality risk (CFR) assessment is an important measure to track record the overall proportion/ratio of the cumulative number of infected patients with the known outcome (confirmed, recovered, or deceased). Considering the ongoing fatality rate, several case-based preventive measures, Coronavirus protein visualization, and approaches to viral vaccine development are discussed herein. The prompt identification of high-risk entities to confront the uncertainty in the risk of death using the approaches highlighted, herein, is of utmost requirement to tackle the current COVID-19 severity. Moreover, the protein visualization available at the viral surface/ body can give further insight into the appropriate vaccine development.
\end{abstract}

Keywords: 2019-nCoV, COVID-19, Respiratory disease, Safety measures, Viral vaccine, Surface proteins, Control precautions

*Correspondence: hafiz.iqbal@tec.mx; Tel.: +52 (81) 83582000 ext. 5679.

(Received: March 15, 2020; accepted: March 19, 2020)

Citation: Muhammad Bilal, Muhammad Shahzad Nazir, Roberto Parra-Saldivar and Hafiz M.N. Iqbal, 2019-nCoV/COVID-19 Approaches to Viral Vaccine Development and Preventive Measures, J. Pure Appl. Microbiol., 2020; 14(1):25-29. https://doi. org/10.22207/JPAM.14.1.05

(C) The Author(s) 2020. Open Access. This article is distributed under the terms of the Creative Commons Attribution 4.0 International License which permits unrestricted use, sharing, distribution, and reproduction in any medium, provided you give appropriate credit to the original author(s) and the source, provide a link to the Creative Commons license, and indicate if changes were made. 


\section{INTRODUCTION}

The severity of COVID-19 and/or transmissibility of 2019-nCoV seems to be higher and broader than expected. It is anticipated that more cases will be spread to other countries and that further transmission may occur, regardless of the original source of 2019-nCoV still remains unknown. In order to overcome this health contingency, it is necessary to consider preventive measures and control precautions. For instance, the timely detention of high-risk entities to confront the issues responsible for the infection is currently needed.

Considering the high-risk trend of 2019nCoV emergence or COVID-19 severity, this is the era of international scientific collaborations. After more than a month in PubMed, one can access more than hundreds articles on COVID-19 or SARSCoV2 as well as many other articles in the article library that have not yet been displayed (Arabi, Murthy, \& Webb, 2020; Guarner, 2020; Iqbal et al., 2020). This is preparatory work on vaccines, therapies, epidemiology, genetics and phylogenetic, diagnoses, clinical aspects, etc. With the popularity of SARS in 2003, it took less than a year to reach less than half of the articles
(Syed, Sopwith, Regan, \& Bellis, 2003). In addition, publications in most scientific journals have open access to studies linked with Coronavirus to disseminate knowledge around the globe. Following a brief introduction, this overview signifies the most available frontiers in the viral vaccine development approaches. Several preventive measures and control precautions are also given with suitable examples. Concerning the ongoing 2019-nCoV/COVID-19 issue, a list of most concerned questions is also given for further insight is future studies.

\section{Frontiers in viral vaccine development}

It is equally important to identify the requisite entities responsible for immunity. Several of the in practice and conventional vaccine development approaches, such as biochemical, immunological, and microbiological, required appropriate cultivation of pathogenic agents (microorganism). Aiming to induce/increase the immune response, DNA as a prime, followed by a protein or a viral vector boost, is used. Figure 1 illustrates several conventional and genomic approaches for viral vaccine development. For effective vaccine development, deep insight into the structure, and available surface protein. The

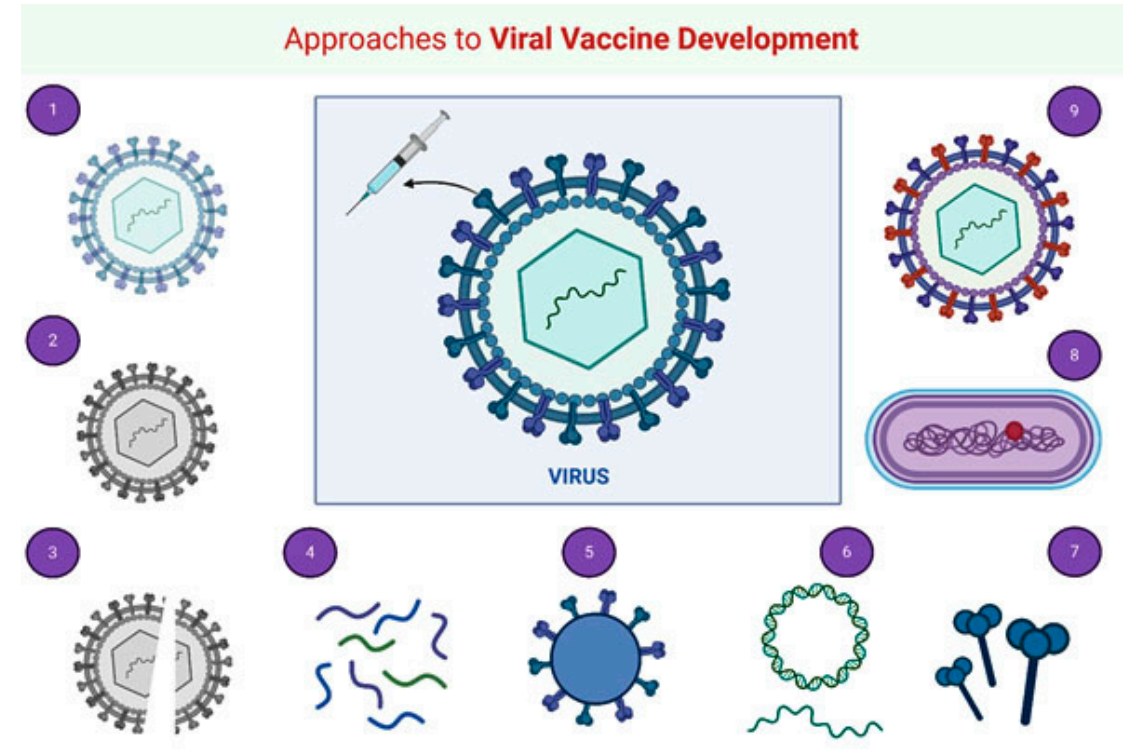

Fig. 1. Schematic illustration of frontiers in viral vaccine development approaches. 1 - Live attenuated, 2 - Whole inactivated, 3 - Split inactivated, 4 - Synthetic peptides, 5 - Virus-like particles, 6 - DNA or RNA, 7 - Recombinant subunits, 8 - Recombinant bacterial vectors, and 9 - Recombinant viral vectors. The $\neg$ Figure was created with "BioRender.com" template and exported under the terms of premium subscription 
2019-nCoV structure and its protein visualization for active vaccine development are shown in Figure 2. As compared to the conventional viral vaccine development approach, the whole genome sequence-based approaches have entirely changed the vaccine development and introduced a new way of thinking in this process.

Rapid response - Infection prevention and control Hospital transmission to other patients and to health care personnel were key features of the two SARS, MERS, and now COVID-19 outbreaks (Jung et al., 2020). In one report, 41\% of COVID-19 hospitalizations were hospital-based, including patients and health workers admitted for other reasons. Intensive caregivers must adopt strict isolation measures in the intensive care unit to protect personnel, other patients, and visitors. At present, it is recommended to take precautions to prevent contact and fall, as well as precautions in the air during aerosol generation (Pang, Bauer, \& Haisch, 2020). Due to concerns about the virus' long-term survival in inanimate environments, special attention should be paid to disinfecting the environment of the intensive care unit. The intensive care physician should be kept up to date and contact the local health department to inform them of their regional infection control strategy. During an epidemic, the consumption of consumables (such as medical masks and N95 masks, alcohol-based hand sanitizers, and surface disinfectants) required to control infections will increase dramatically (Glatt, 2020). Ensuring an appropriate supply chain from the manufacturer to the front line is critical to reducing spread within the hospital.

\section{Fatality rate of old age people}

There is a direct link between mortality and age. Therefore, if a person is in between 60 and 69 years old, the mortality rate is $3.6 \%$. From 70 to $79.8 \%$. If 80 or older, it is $15 \%$. In some areas, it is even higher, at $18 \%$. Older people are more susceptible to acute respiratory distress syndrome, an acute lung injury that causes many deaths (Wang, Tang, \& Wei, 2020). However, it appears that the virus is more likely to affect the heart than any similar virus. Therefore, what they actually saw were COVID-19 patients who died of a heart attack. In a dialysis center in Wuhan, many patients died of coronavirus without pneumonia, which only put pressure on the body. Pneumonia does not necessarily have to kill the infected person. The side effect of the coronavirus on the health system is that we have seen that older people are more likely to die from other causes. Older people are

\section{Coronavirus Structure and Protein Visualization}

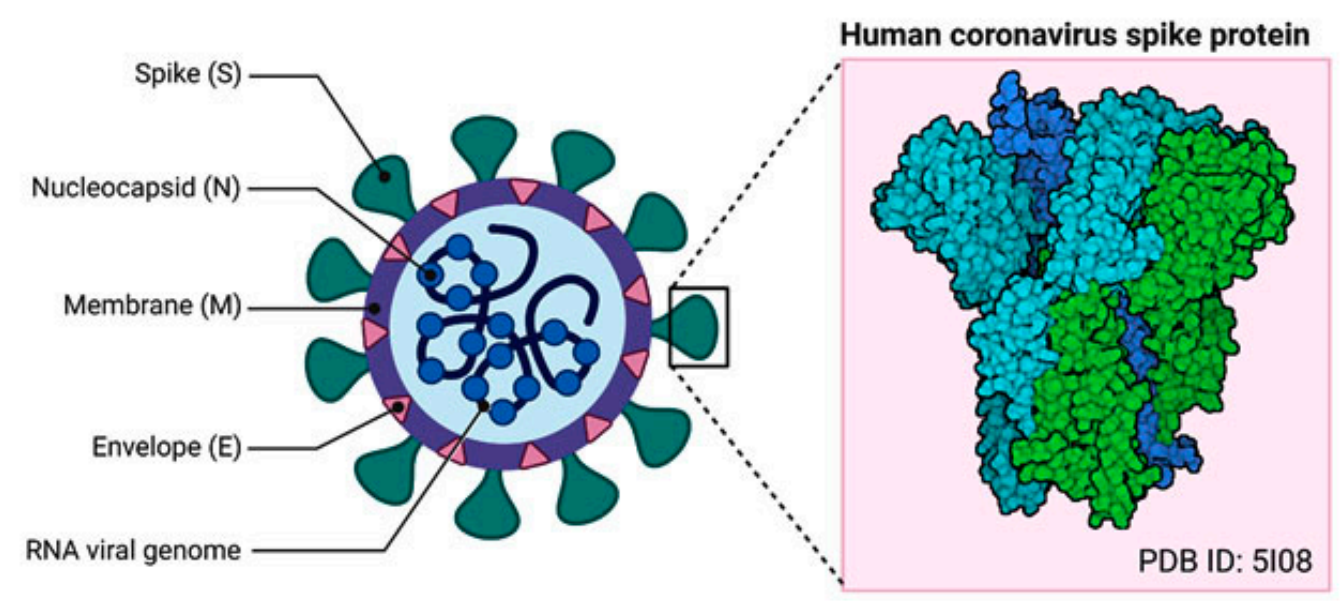

Fig. 2. The 2019-nCoV structure and its protein visualization for active vaccine development. Coronaviruses belong in the family Coronaviridae and can cause disease in mammals and birds. The coronavirus spike (S) protein mediates membrane fusion by binding to cellular receptors. The $\neg$ Figure was created with "BioRender. com" template and exported under the terms of premium subscription 
hospitalized much more often than young people are and do not get the quality they deserve during an epidemic.

Workforce safety measures/Impacts on health workers

COVID-19 has considered a viral disease. Protecting medical staff and related workers is another major challenge. Diseased increase the severity of the epidemic, as medical staff with respiratory symptoms are required to stay home until test results are available and because the patient has a contact infection (Wang et al., 2020). Caring for infected patients faces a significant risk of exposure to intensive care unit personnel, as the critically ill patients they meet may produce higher viruses and more extended illnesses. Health workers with MERS, SARS, and COVID-19 have experienced severe infections and deaths, which has placed tremendous social and psychological pressure on workers. During the outbreaks of SARS and MERS, health-care staffs expressed concern about the health of themselves and their families and described the painful experiences of anxiety, fear, and even social predisposition and stigma (Lee \& Hsueh, 2020). In addition, paramedics will require significant mental health support. Getting someone's attention or rationing attention can be very painful, especially for those who remind you of your grandmother. There is much debate about what to do when medical personnel is exposed. In California, only one patient is in contact with 200 health workers, so they must isolate themselves. However, most hospitals are already busy during the flu season, and COVID-19 will overwhelm them, so they cannot afford to lose medical staff (Ziff \& Ziff, 2020). Most importantly, universal precautions need to be taken, and every patient treated the same. Most people are familiar with general precautions during the HIV epidemic. The stigma is such that they end up treating every patient like HIV, which is an effective measure.

\section{9-nCoV - Most concerned question}

- How much do we know about the human-tohuman transmission of 2019-nCoV?

- Does the 2019-nCoV appear to be significantly contagious in a human-to-human context?

- What makes 2019-nCoV strain significantly concerning, regardless its resembling symptoms from common cold to as severe as SARS?
- How concerned should we be about the 2019$\mathrm{nCoV}$ origin, regardless the fact that there are more confirmed cases around the globe and the infected cases are keep growing?

- What are the main symptoms of 2019-nCoV and how they are distinguishable compared to typical common cold and seasonal flu?

-What do people need to know to take preventive measures to protect themselves and avoid getting sick?

- Are the currently available viral vaccine development approaches good enough to tackle 2019-nCoV, effectively?

\section{ACKNOWLEDGMENTS}

All listed author(s) are thankful to their representative universities/institutes for providing the related support to compile this work.

\section{CONFLICT OF INTEREST}

The listed author(s) declare no conflict of interest in any capacity, including competing or financial.

\section{AUTHORS' CONTRIBUTION}

All listed author(s) have made a substantial, direct and intellectual contribution to the work, and approved it for publication.

\section{FUNDING}

None.

\section{ETHICS STATEMENT}

This article does not contain any studies with human participants or animals performed by any of the authors.

\section{AVAILABILITY OF DATA}

Not applicable.

\section{REFERENCES}

1. Arabi, Y. M., Murthy, S., \& Webb, S. COVID-19: a novel coronavirus and a novel challenge for critical care. Intensive Care Medicine, 2020; 1-4. https://doi. org/10.1007/s00134-020-05955-1

2. Glatt, A. E. Health care worker use of $\mathrm{N} 95$ respirators vs medical masks did not differ for workplace-acquired influenza. Annals of Internal Medicine, 2020; 172(2), JC7-JC7. https://doi.org/10.7326/ACPJ202001210-007

3. Guarner, J. Three Emerging Coronaviruses in Two Decades: The Story of SARS, MERS, and Now COVID-19: Oxford University Press US 2020. 
4. Iqbal, H.M.N., Romero-Castillo, K.D., Bilal, M., \& Parra-Saldivar, R. The Emergence of Novel-Coronavirus and its Replication Cycle -An Overview. J Pure Appl. Microbiol., 2020 ; 14(1), In Press.

5. Jung, S.-m., Akhmetzhanov, A. R., Hayashi, K., Linton, N. M., Yang, Y., Yuan, B., . . . Nishiura, H. Real-time estimation of the risk of death from novel coronavirus (covid-19) infection: Inference using exported cases. Journal of clinical medicine, 2020 ; 9(2), 523. https:// doi.org/10.3390/jcm9020523

6. Lee, P.-I., \& Hsueh, P.-R. Emerging threats from zoonotic coronaviruses-from SARS and MERS to 2019-nCoV. Journal of Microbiology, Immunology and Infection 2020. https://doi.org/10.1016/j.jmii.2020.02.001

7. Pang, G. A., Bauer, M., \& Haisch, C. (2020). Aerosol generation from laser-ablation-synthesized nanoparticles. Paper presented at the Synthesis and Photonics of Nanoscale Materials XVII. https://doi. org/10.1117/12.2543021

8. Syed, Q., Sopwith, W., Regan, M., \& Bellis, M. Behind the mask. Journey through an epidemic: some observations of contrasting public health responses to SARS. Journal of Epidemiology \& Community Health, 2003; 57(11), 855-856. https://doi.org/10.1136/ jech.57.11.855

9. Wang, W., Tang, J., \& Wei, F. Updated understanding of the outbreak of 2019 novel coronavirus (2019-nCoV) in Wuhan, China. Journal of medical virology 2020. https://doi.org/10.1002/jmv.25689

10. Ziff, A.L. and Ziff, R. M. Fractal kinetics of COVID-19 pandemic. medRxiv 2020. https://doi. org/10.1101/2020.02.16.20023820 